\title{
AN APPROACH TO THE PRODUCTION PLANT LOCATION SELECTION BASED ON THE USE OF THE ATANASSOV INTERVAL-VALUED INTUITIONISTIC FUZZY SETS
}

\author{
Dragiša STANUJKIĆ ${ }^{1^{*}}$, Ieva MEIDUTE்-KAVALIAUSKIENÉ ${ }^{2}$ \\ ${ }^{1}$ Technical Faculty in Bor, University of Belgrade, Serbia \\ ${ }^{2}$ Faculty of Business Management, Vilnius Gediminas Technical University, Vilnius, Lithuania
}

Received 10 June 2015; revised 20 June 2016, 4 August 2016; accepted 5 September 2016; published online 17 May 2017

\begin{abstract}
Location planning is one of very important tasks in the manufacturing industry. There are various factors that influence the selection of a location of a production plant. In cases of selection, when uncertainty and a need for predicting are significantly manifested, the use of fuzzy or grey numbers can be very useful. That is why an approach based on the use of Interval-Valued Intuitionistic Fuzzy Numbers (IVIFNs) for the selection of the most appropriate location of a production plant is considered in this article. The efficiency of the proposed approach is considered on an example, based on the real problem of the smelter and refinery production plant selection.
\end{abstract}

Keywords: facility location selection, production allocation problem, intuitionistic fuzzy sets, interval-valued intuitionistic fuzzy numbers, score function.

\section{Introduction}

Over the last decades, Multiple-Criteria Decision-Making (MCDM) has been successfully used to solve numerous decision-making problems. However, the classical MCDM methods, usually based on the use of crisp numbers, have not been adequate for solving many realworld decision-making problems.

The significant progress in the MCDM was made after Zadeh (1965) had proposed his fuzzy sets theory, which allows partial belonging to a set. Based on the fuzzy set theory, Bellman and Zadeh (1970) also proposed Fuzzy MCDM (FMCDM) and thus enabled the solving of MCDM problems in a much more adequate manner.

Evident progress has also been made since Atanassov (1986) proposed the Intuitionistic Fuzzy Sets (IFS) Theory, as an extension of the FS theory, which additionally introduces not belonging to a set, thus allowing the use of the MCDM for solving a number of more complex problems. Up to now, the IFS has been successfully used to solve many decision-making problems, such as: Szmidt, Kacprzyk (1996, 2000, 2002); De et al. (2000); Atanassov et al. (2002); Li (2005); Wei et al. (2010); Wei (2011); Xu (2011); Wei, Zhao (2012); Shen et al. (2015); $\mathrm{Xu}$, Liao (2015), and has also got significant extensions.
Atanassov and Gargov (1989) introduced the Interval-Valued Intuitionistic Fuzzy Set (IVIFS), the important characteristic of which is that the values of its membership function and non-membership function are intervals rather than exact numbers (Wang 2008). Based on the application of IVIFSs, a larger number of decision-making problems associated with uncertainties and forecasting can more efficiently and easily be solved.

The selection of a production plant location can be mentioned as one of such problems. The strategic selection of a production plant location is related to the influence of many factors that may be conflicting in nature. In the last few decades, in terms of cost management, a site selection or more precisely a production plant selection has been considered in some papers as part of a much wider problem of the supply chain management, such as Mairs et al. (1978); Chandra, Fisher (1994); Badri (1999); Jayaraman, Pirkul (2001); Liu, Papageorgiou (2013) and Maric et al. (2014). In these papers, the selection of the optimal site location was mainly determined on the basis of mixed integer programming.

The site, or location, selection problem is also considered as an MCDM problem in many studies. For example, Barda et al. (1990) used the ELECTRE III method in order to determine the best location for thermal

${ }^{\star}$ Corresponding author. E-mail: dstanujkic@tfbor.bg.ac.rs 
power. Liang, Wang (1991); Chou (2007) and Chou et al. (2008) proposed the use of fuzzy group multiple-criteria decision-making approaches for the location selection problem. Mousavi et al. (2013) used three MCDM methods, namely Delphi, the AHP and PROMETHEE, in order to make the best selection for the plant location. Ray et al. (2015) considered the location selection problem based on the use of several MCDM methods, i.e. the TOPSIS, the SAW, the GRA, the MOORA and the ELECTRE methods.

The transportation costs as well as storage and manipulation costs usually have a significant impact on production costs and they are often significantly associated with the site selection problem. In the case of capital investments, especially in cases of long-term investments characterized by significant price variations of raw materials and/or products, these costs can be very significant.

To provide a MCDM model capable to deal with uncertainties and predictions related to solving numerous real-world decision-making problems, there is one model based on the use of the IVIFSs considered in this paper. Therefore, this paper is organized as follows: In the preliminaries of Section 1, some basic elements of the IFS theory as well as some elements relevant to the proposed approach are discussed. In Section 2, an approach for selecting the most acceptable alternative based on the use of the IVIFSs and the score function is proposed. In Section 3, an example based on the real plant location selection problems is discussed with the aim to explain in detail the proposed methodology and to point out its efficiency as well as to identify its possible weaknesses. Finally, the conclusions are presented.

\section{Preliminaries}

In this section, some basic definitions and notations relevant for the proposed approach are considered.

\subsection{The basic concepts of the Atanassov IFS}

As previously mentioned, the Atanassov IFSs were proposed by Atanassov (1986) as an extension of the FSs theory proposed by Zadeh (1965). In addition to the belonging to a set proposed in the fuzzy set theory, in the IFSs theory, Atanassov (1986) also introduced not belonging to a set. Therefore, an IFS $\tilde{A}$ in universe of discourse $X$ can be defined as follows:

$$
\tilde{A}=\left\{\left\langle x, \mu_{A}(x), v_{A}(x)\right\rangle \mid x \in X\right\},
$$

where: $\mu_{A}(x)$ and $v_{A}(x)$ denote the degree of the membership and the degree of the non-membership of the element $x$ to the set $\tilde{A}$, respectively; $\mu_{A}: X \rightarrow[0,1]$ and $v_{A}: X \rightarrow[0,1]$, with the following condition:

$$
0 \leq \mu_{A}(x)+v_{A}(x) \leq 1 \text {. }
$$

In addition, the IFSs also introduced an additional important parameter called the degree of indeterminacy, $\pi_{A}(x)$ of $x$ to $\tilde{A}$, as follows:

$$
\pi_{A}(x)=1-\mu_{A}(x)-v_{A}(x),
$$

with the following condition:

$$
\pi_{A}(x) \in[0,1] .
$$

Basic operations on IFSs. The operations of addition and multiplication on the IFSs have been defined by Atanassov (1994). Let $\tilde{A}=\left\langle\mu_{A}, v_{A}\right\rangle$ and $\tilde{B}=\left\langle\mu_{B}, v_{B}\right\rangle$ be two IFSs. Then, the basic operations on IFSs can be defined as follows:

$$
\begin{gathered}
\tilde{A}+\tilde{B}=\left\langle\mu_{A}+\mu_{B}-\mu_{A} \mu_{B}, v_{A} v_{B}\right\rangle ; \\
\tilde{A} \cdot \tilde{B}=\left\langle\mu_{A} \mu_{B}, v_{A}+v_{B}-v_{A} v_{B}\right\rangle .
\end{gathered}
$$

In addition to the above presented, the following operations on IFS are also significant:

$$
\begin{aligned}
& \lambda \tilde{A}=\left\langle 1-\left(1-\mu_{A}\right)^{\lambda}, v^{\lambda}\right\rangle ; \\
& \tilde{A}^{\lambda}=\left\langle\mu_{A}^{\lambda}, 1-\left(1-v_{A}\right)^{\lambda}\right\rangle,
\end{aligned}
$$

where $\lambda$ denotes a real number; $\lambda>0$.

The score function of IFSs. Let $\tilde{A}=\left\langle\mu_{A}, v_{A}\right\rangle$ be an IFSs. Then, the score function $S_{\tilde{A}}$ of $\tilde{A}$ is as follows (Chen, Tan 1994):

$$
S_{A}=\mu_{A}-v_{A},
$$

where: $S_{\tilde{A}} \in[-1,1]$.

The accuracy function of IFSs. Let $\tilde{A}=\left\langle\mu_{A}, v_{A}\right\rangle$ be an IFS. Then, the accuracy function $H_{\tilde{A}}$ of $\tilde{A}_{\text {is }}$ as follows (Hong, Choi 2000):

$$
H_{\tilde{A}}=\mu_{A}+v_{A},
$$

where: $H_{\tilde{A}} \in[0,1]$.

Intuitionistic Weighted Arithmetic Mean (IWAM) of IFSs. Let $\tilde{A}_{j}=\left\langle\mu_{A_{j}}, v_{A_{j}}\right\rangle$ be a collection of IFSs. The IWAM of the dimensions $n$ is the mapping $I W A M: R^{n} \rightarrow R$ that has an associated weighting vector $W=\left(w_{1}, w_{2}, \ldots, w_{n}\right)^{T}$, such as:

$$
\begin{aligned}
& \operatorname{IWAM}\left(\tilde{A}_{1}, \tilde{A}_{2}, \ldots, \tilde{A}_{n}\right)=\sum_{j=1}^{n} w_{j} \tilde{A}_{j}= \\
& \left\langle 1-\prod_{j=1}^{n}\left(1-\mu_{A_{j}}\right)^{w_{j}}, \prod_{j=1}^{n} v_{A_{j}}^{w_{j}}\right\rangle,
\end{aligned}
$$

where: $w_{j} \in[0,1]$ and $\sum_{j=1}^{n} w_{j}=1$.

According to Dymova and Sevastjanov (2011) the IWAM can be obtained by applying Equations (5) and (7).

\subsection{Interval-valued intuitionistic fuzzy numbers}

The Interval-Valued Intuitionistic Fuzzy Number (IVIFN) $\tilde{A}=\left\langle[l, u],\left[l^{\prime}, u^{\prime}\right]\right\rangle$ shown in Figure is defined by the membership $\mu_{A}(x)$ and the non-membership $v_{A}(x)$ function, respectively, as follows:

$$
\mu(x)= \begin{cases}1, & l \leq x \leq u \\ 0, & \text { otherwise }\end{cases}
$$




$$
v(x)= \begin{cases}1, & l^{\prime} \leq x \leq u^{\prime} \\ 0, & \text { otherwise }\end{cases}
$$

where: the parameters $l$ and $u$ indicate the smallest possible value and the largest possible value describing belonging to a set, respectively, and the parameters $l^{\prime}$ and $u^{\prime}$ indicate the smallest possible value and the largest possible value describing not belonging to a set, respectively.

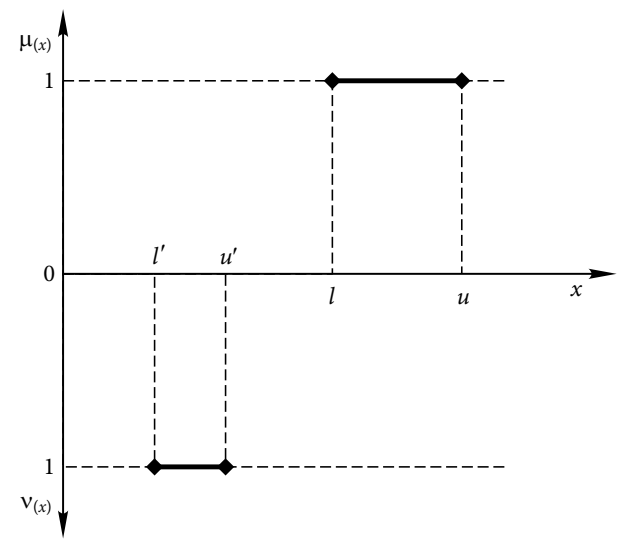

Figure. An interval-valued intuitionistic fuzzy number

Basic arithmetic operations on IVIFNs. Let $\tilde{A}=\left\langle\left[a_{l}, a_{u}\right],\left[a_{l}^{\prime}, a_{u}^{\prime}\right]\right\rangle$ and $\tilde{B}=\left\langle\left[b_{l}, b_{u}\right],\left[b_{l}^{\prime}, b_{u}^{\prime}\right]\right\rangle$ be two IVIFNs. Then, according to Equations (5) and (6), the operations of addition and multiplication on IVIFNs are as follows:

$$
\begin{aligned}
& \tilde{A}+\tilde{B}=\left\langle\left[a_{l}+b_{l}-a_{l} b_{l}, a_{u}+b_{u}-a_{u} b_{u}\right],\right. \\
& \left.\left[a_{l}^{\prime} b_{l}^{\prime}, a_{u}^{\prime} b_{u}^{\prime}\right]\right\rangle ; \\
& \tilde{A} \cdot \tilde{B}=\left\langle\left[a_{l} b_{l}, a_{u} b_{u}\right],\right. \\
& \left.\left[a_{l}^{\prime}+b_{l}^{\prime}-a_{l}^{\prime} b_{l}^{\prime}, a_{u}^{\prime}+b_{u}^{\prime}-a_{u}^{\prime} b_{u}^{\prime}\right]\right\rangle .
\end{aligned}
$$

The score function of IVIFNs. Let $\tilde{A}=\left\langle\left[a_{l}, a_{u}\right]\right.$, $\left.\left[a_{l}^{\prime}, a_{u}^{\prime}\right]\right\rangle$ be an IVIFN. The Score $S_{\tilde{A}}$ function of $\tilde{A}$ is as follows (Xu 2007; Xu, Chen 2007):

$$
S_{\tilde{A}}=\frac{a_{l}-a_{l}^{\prime}+a_{u}-a_{u}^{\prime}}{2},
$$

where $S_{\tilde{A}} \in[-1,1]$.

The score function of IVIFNs. Let $\tilde{A}=\left\langle\left[a_{l}, a_{u}\right]\right.$, $\left.\left[a_{l}^{\prime}, a_{u}^{\prime}\right]\right\rangle$ be an IVIFN. The accuracy function $H_{\tilde{A}}$ of $\tilde{A}$ is as follows (Xu 2007; Xu, Chen 2007):

$$
H_{\tilde{A}}=\frac{a_{l}+a_{l}^{\prime}+a_{u}+a_{u}^{\prime}}{2},
$$

where $H_{\tilde{A}} \in[0,1]$.

Interval-valued Intuitionistic Fuzzy Weighted Averaging (IVIFWA) operator. Let $\tilde{A}_{j}=\left\langle\left[l_{j}, u_{j}\right],\left[l_{j}^{\prime}, u_{j}^{\prime}\right]\right\rangle$ be a collection of IVIFNs. Then, the IVIFWA operator of the dimensions $n$ is the mapping IVIFWA $: R^{n} \rightarrow R$ that has an associated weighting vector $W=\left(w_{1}, w_{2}, \ldots, w_{n}\right)^{T}$ was defined as (Xu 2007; Xu, Chen 2007):

$$
\begin{aligned}
& \operatorname{IVIFWA}\left(\tilde{A}_{1}, \tilde{A}_{2}, \ldots, \tilde{A}_{n}\right)= \\
& \left\langle\left[1-\prod_{j=1}^{n}\left(1-l_{j}\right)^{w_{j}}, 1-\prod_{j=1}^{n}\left(1-u_{j}\right)^{w_{j}}\right],\right. \\
& \left.\left[\prod_{j=1}^{n}\left(l_{j}^{\prime}\right)^{w_{j}}, \prod_{j=1}^{n}\left(u_{j}^{\prime}\right)^{w_{j}}\right]\right\rangle,
\end{aligned}
$$

where: $w_{j} \in[0,1]$ and $\sum_{j=1}^{n} w_{j}=1$.

Ranking IVIFNs. Let $\tilde{A}$ and $\tilde{B}$ be two IVIFNs. Then, based on $\mathrm{Xu}$ and Yager (2006):

$$
\begin{cases}\tilde{A}<\tilde{B}, & \text { if } \quad S_{\tilde{A}}<S_{\tilde{B}} ; \\ \tilde{A}>\tilde{B}, & \text { if } \quad S_{\tilde{A}}>S_{\tilde{B}},\end{cases}
$$

when $S_{\tilde{A}}=S_{\tilde{B}}$, decisions must be made based on the values of the accuracy function, i.e.:

$$
\left\{\begin{array}{l}
\tilde{A}<\tilde{B}, \quad \text { if } \quad H_{\tilde{A}}<H_{\tilde{B}} ; \\
\tilde{A}=\tilde{B}, \text { if } \quad H_{\tilde{A}}=H_{\tilde{B}} ; \\
\tilde{A}>\tilde{B}, \text { if } \quad H_{\tilde{A}}>H_{\tilde{B}} .
\end{array}\right.
$$

\subsection{Linguistic variables adapted for use with IVIFNs}

The linguistic variables have been extensively used by many authors for solving various decision-making problems; as a result, numerous linguistic scales (variables) are also proposed.

In this approach, a specific linguistic scale adapted to work with IVIFNs is proposed. The proposed linguistic scale is shown in Table 1.

Table 1. Linguistic variables for expressing satisfaction and dissatisfaction levels

\begin{tabular}{|l|c|}
\hline \multicolumn{1}{|c|}{ Linguistic variable } & $\begin{array}{c}\text { The corresponding interval } \\
\text { fuzzy numbers }\end{array}$ \\
\hline Absolutely High (AH) & {$[0.95,1.00]$} \\
\hline Extremely High (EH) & {$[0.85,0.95]$} \\
\hline Very High (VH) & {$[0.75,0.85]$} \\
\hline High (H) & {$[0.65,0.75]$} \\
\hline Moderate High (MH) & {$[0.55,0.65]$} \\
\hline Moderate (M) & {$[0.45,0.55]$} \\
\hline Moderate Low (ML) & {$[0.35,0.45]$} \\
\hline Low (L) & {$[0.25,0.35]$} \\
\hline Very Low (VL) & {$[0.15,0.25]$} \\
\hline Extremely Low (EL) & {$[0.05,0.15]$} \\
\hline Absolutely Low (AL) & {$[0.00,0.05]$} \\
\hline
\end{tabular}


Table 2. The acceptable combinations of linguistic variables

\begin{tabular}{|l|l|l|l|l|l|l|l|l|l|c|c|}
\hline \multirow{2}{*}{ Satisfaction level } & \multicolumn{7}{c|}{ Dissatisfaction level and degree of indeterminacy } \\
\cline { 2 - 12 } & $\mathrm{AH}$ & $\mathrm{EH}$ & $\mathrm{VH}$ & $\mathrm{H}$ & $\mathrm{MH}$ & $\mathrm{M}$ & $\mathrm{ML}$ & $\mathrm{L}$ & $\mathrm{VL}$ & $\mathrm{EL}$ & $\mathrm{AL}$ \\
\hline Absolutely High (AH) & & & & & & & & & & & \\
\hline Extremely High (EH) & & & & & & & & & & & 0.00 \\
\hline Very High (VH) & & & & & & & & & & 0.00 & 0.10 \\
\hline High (H) & & & & & & & & & 0.00 & 0.10 & 0.20 \\
\hline Moderate High (MH) & & & & & & & & 0.00 & 0.10 & 0.20 & 0.30 \\
\hline Moderate (M) & & & & & & & 0.00 & 0.10 & 0.20 & 0.30 & 0.40 \\
\hline Moderate Low (ML) & & & & & & 0.00 & 0.10 & 0.20 & 0.30 & 0.40 & 0.50 \\
\hline Low (L) & & & & & 0.00 & 0.10 & 0.20 & 0.30 & 0.40 & 0.50 & 0.60 \\
\hline Very Low (VL) & & & & 0.00 & 0.10 & 0.20 & 0.30 & 0.40 & 0.50 & 0.60 & 0.70 \\
\hline Extremely Low (EL) & & & 0.00 & 0.10 & 0.20 & 0.30 & 0.40 & 0.50 & 0.60 & 0.70 & 0.80 \\
\hline Absolutely Low (AL) & & 0.00 & 0.10 & 0.20 & 0.30 & 0.40 & 0.50 & 0.60 & 0.70 & 0.80 & 0.90 \\
\hline
\end{tabular}

In this approach, the same linguistic variables are applied for indicating the level of satisfaction and the level of dissatisfaction. The corresponding IVIFN is formed on the basis of interval fuzzy numbers belonging to the selected linguistic variables that describe the satisfaction and dissatisfaction levels. In order to satisfy the condition (4), i.e. the condition according to which the degree of indeterminacy should be less than or equal to one, the acceptable combinations of the linguistic variables that can be used for expressing satisfaction and dissatisfaction levels are accounted for in Table 2.

The degrees of indeterminacy in Table 2 are calculated as follows:

$$
\pi_{A}(x)=1-a_{u}-a_{u}^{\prime} .
$$

\section{An approach for selecting the best alternative based on the use of IVIFNs and the score function}

In this section, an approach based on the use of the linguistic variables adapted for use with IVIFNs and the Score Function is proposed. The detailed step-by-step computational procedure of the proposed approach can precisely be expressed by using the following steps:

Step 1. Identify available alternatives and select evaluation criteria. In this step, a team of decision-makers/experts identify available alternatives and choose criteria for their evaluation. Due to certain advantages, which IVIFNs provide, an adequate evaluation of such alternatives can be made based on a set with a smaller number of much more complex evaluation criteria.

Step 2. Determine the relative importance of the evaluation criteria. In the literature, many techniques are proposed for determining weights of criteria such as pair-wise comparisons (Saaty 1977), the Delphi Method (Hwang, Lin 1987), the Entropy Approach (Hwang, Yoon 1981) and the SWARA Technique (Keršulienè et al. 2010).

In this approach, any of them can be used.

Step 3. Construct the interval-valued fuzzy decision matrix for each decision-maker. In this step, each decision-maker makes his or her own evaluation matrix in which alternatives are evaluated by using the linguistic variables from Table 1 . To meet the condition (4), the surveyed experts were recommended to use acceptable combination of the linguistic variables from Table 2.

After that, such linguistic variables are transformed into corresponding IVIFNs and, in accordance with their preferences, some parameters of IVIFNs are modified, if necessary.

As a result of performing this step, each decisionmaker has formed his or her evaluation matrix, whose elements are IVIFNs.

Step 4. Construct the group interval-valued fuzzy decision-making matrix. In this approach, the IVIFWA aggregation operator is proposed for constructing the group decision-making matrix based on individual evaluation matrices.

Step 5. Calculate the overall interval-valued intuitionistic fuzzy performance rating of each alternative. As in the previous step, the overall interval-valued intuitionistic fuzzy performance rating of each alternative can be calculated by using the IVIFWA operator, i.e. by applying Equation (18).

Step 6. Determine the Score Function of each alternative. The score function of each alternative can be determined by using Equation (16).

Step 7. Rank the alternatives. The considered alternatives are ranked on the basis of their $S_{i}$ and the alternative with the highest $S_{i}$ is the one placed the best.

In a particular case, when some of alternatives have the same significance based on their $S_{i}$ the best placed alternative can be determined on the basis of their $H_{i}$, that is by using Equation (17).

\section{A case study}

A mining and smelting company should replace its copper smelter and refinery primarily because of the old smelting technology, which results in significant air pollution and the lower utilization of copper and other valuable metals. 
Based on the planned objectives, a new conceptual design for the smelter and refinery is proposed. However, the high investment costs required for the construction of a new copper smelter as well as the currently insufficient amount of copper concentrate have made the two additional alternatives even more topical.

As an alternative to constructing the new smelter and refinery plant, a group of experts indicate some advantages that can be obtained by smelting and refining copper concentrates in another smelter and refinery plant. The nearest copper smelter, the Pirdop copper smelter and refinery, is located about $300 \mathrm{~km}$ away from the mining and smelting company, whereby the transport of concentrate will be carried by rail. In doing so, a part of the funds planned to build the new smelter and refinery could be invested in mining production in order to increase its efficiency and capacity.

Another group of experts emphasize the insufficient capacity of mining production, i.e. the insufficient quantity of the copper concentrate produced in the mining and smelter company. To achieve lower production costs, it is proposed that the new smelter should apply the autogenous smelting process that requires a continuous consumption of a certain quantity of copper concentrate. Therefore, these experts emphasize that, even at the minimum melting capacity, a significant portion of concentrate would have to be purchased and delivered to the location of the new smelter. Due to the geographical positions of the companies selling copper concentrate, this group of experts stress that transport costs could be too high, thus casting a doubt to the economic viability of investment in the construction of the new smelter and refinery.

They also point out that there is a possibility of the dislocation of the new smelter and refinery, i.e. its construction at the site next to the Port of Prahovo on the Danube River, about $80 \mathrm{~km}$ away from the mining and smelting company. If this were done, the costs of the loading and transportation of the purchased concentrates from the Port of Prahovo to the new smelter would be avoided. The justification of the dislocation of the new smelter is argued by stating the fact that, in the long period of time, most of concentrate will have to be purchased.

To solve this problem, the best solution on whose realization a focus should be put on is selected; a group of experts were established with the aim to evaluate the above-considered alternatives from the short-term (S), medium-term $(\mathrm{M})$ and long-term $(\mathrm{L})$ points of view.

Due to the complexity of the problem and the need to perform certain predictions such as an assessment of the copper prices and the availability and prices of copper concentrate on the world market at some future time, the use of IVIFNs is proposed for an evaluation of alternatives.

The procedure used for evaluating the alternatives is described in detail below. For the reason of simplicity, the evaluation is presented based on the responses of the three experts.
At the beginning of the evaluation process, the experts discussed in detail the advantages and disadvantages of the alternatives presented in Table 3.

After that, the experts carried out an evaluation of the alternatives in relation to the short-term, mediumterm and long-term exploitation by using the linguistic variables from Table 1. On that occasion, the experts expressed their attitudes about the advantages and disadvantages that may arise from the use of such alternatives in the above-mentioned periods of exploitation, simultaneously trying to satisfy the condition (4).

The results obtained from the three experts during the evaluation are displayed in Tables 4-6.

After that, Tables 4-6 are transformed into a form suitable for a further evaluation, as it is shown in Tables 7-9. During this transformation, linguistic variables are transformed into corresponding numerical values in accordance with Table 1.

Table 3. The available alternatives

\begin{tabular}{|c|l|}
\hline Alternatives & \multicolumn{1}{|c|}{ Short description } \\
\hline$A_{1}$ & $\begin{array}{l}\text { The construction of the copper smelter and } \\
\text { refinery at the location of the mining and } \\
\text { smelting company }\end{array}$ \\
\hline$A_{2}$ & $\begin{array}{l}\text { The processing of the copper concentrate in } \\
\text { the Pirdop copper smelter and refinery }\end{array}$ \\
\hline$A_{3}$ & $\begin{array}{l}\text { The construction of the copper smelter } \\
\text { and refinery at the site next to the Port of } \\
\text { Prahovo }\end{array}$ \\
\hline
\end{tabular}

Table 4. The responses obtained from the first one of the three experts

\begin{tabular}{|c|c|c|c|c|c|c|}
\hline \multirow{2}{*}{ Alternatives Criteria } & \multicolumn{2}{|c|}{ S } & \multicolumn{2}{c|}{ M } & \multicolumn{2}{c|}{$\mathrm{L}$} \\
\cline { 2 - 7 } & $\mu$ & $\nu$ & $\mu$ & $v$ & $\mu$ & $v$ \\
\hline$A_{1}$ & $\mathrm{ML}$ & $\mathrm{MH}$ & $\mathrm{M}$ & $\mathrm{ML}$ & $\mathrm{H}$ & $\mathrm{VL}$ \\
\hline$A_{2}$ & $\mathrm{M}$ & $\mathrm{M}$ & $\mathrm{M}$ & $\mathrm{VL}$ & $\mathrm{ML}$ & $\mathrm{MH}$ \\
\hline$A_{3}$ & $\mathrm{ML}$ & $\mathrm{ML}$ & $\mathrm{M}$ & $\mathrm{M}$ & $\mathrm{M}$ & $\mathrm{VL}$ \\
\hline
\end{tabular}

Table 5. The responses obtained from the second one of the three experts

\begin{tabular}{|c|c|c|c|c|c|c|}
\hline \multirow{2}{*}{ Criteria } & \multicolumn{2}{|c|}{$\mathrm{S}$} & \multicolumn{3}{c|}{ M } & \multicolumn{2}{c|}{$\mathrm{L}$} \\
\cline { 2 - 8 } & $\mu$ & $v$ & $\mu$ & $\nu$ & $\mu$ & $v$ \\
\hline$A_{1}$ & $\mathrm{M}$ & $\mathrm{M}$ & $\mathrm{M}$ & $\mathrm{ML}$ & $\mathrm{MH}$ & $\mathrm{ML}$ \\
\hline$A_{2}$ & $\mathrm{MH}$ & $\mathrm{ML}$ & $\mathrm{ML}$ & $\mathrm{L}$ & $\mathrm{ML}$ & $\mathrm{M}$ \\
\hline$A_{3}$ & $\mathrm{H}$ & $\mathrm{L}$ & $\mathrm{H}$ & $\mathrm{VL}$ & $\mathrm{M}$ & $\mathrm{L}$ \\
\hline
\end{tabular}

Table 6. The responses obtained from the third one of the three experts

\begin{tabular}{|c|c|c|c|c|c|c|}
\hline \multirow{2}{*}{ Clternatives } & \multicolumn{2}{|c|}{$\mathrm{S}$} & \multicolumn{3}{c|}{$\mathrm{M}$} & \multicolumn{2}{c|}{$\mathrm{L}$} \\
\cline { 2 - 7 } & $\mu$ & $\nu$ & $\mu$ & $\nu$ & $\mu$ & $\nu$ \\
\hline$A_{1}$ & $\mathrm{M}$ & $\mathrm{M}$ & $\mathrm{M}$ & $\mathrm{ML}$ & $\mathrm{M}$ & $\mathrm{L}$ \\
\hline$A_{2}$ & $\mathrm{VH}$ & $\mathrm{VL}$ & $\mathrm{ML}$ & $\mathrm{MH}$ & $\mathrm{ML}$ & $\mathrm{MH}$ \\
\hline$A_{3}$ & $\mathrm{M}$ & $\mathrm{VL}$ & $\mathrm{H}$ & $\mathrm{L}$ & $\mathrm{H}$ & $\mathrm{M}$ \\
\hline
\end{tabular}


After having transformed the linguistic variables in the recommended quantitative values, i.e. intervals, the experts were allowed to adjust the values in accordance with their preferences and the fulfilment of the condition (Equation (4)) is rechecked.

The group performance ratings obtained by using the IVIFWA operator, i.e. by applying Equation (18), are shown in Table 10. In this transformation, the following significances: $w_{d m 1}=0.36, w_{d m 2}=0.34$, and $w_{d m 3}=0.30$, were given to the experts.

The overall performance ratings of the alternatives obtained by applying Equation (18) are shown in Table 11 . In this case, to the long- and the medium-term periods of exploitation are given somewhat greater importance compared to the short-term one.

Table 12 shows the value of the Score Function of the considered alternatives determined by applying Equation (16) as well as their ranking order.

In addition to the ranking of the alternatives, the proposed model can be applied for a certain analysis. An analysis of different scenarios can be carried out by giving different weights to the long-, medium- and shortterm periods of use.
Table 11. The overall performance ratings of the alternatives

\begin{tabular}{|c|c|}
\hline Alternatives & $\tilde{S}_{i}$ \\
\hline$A_{1}$ & $\langle[0.48,0.58],[0.30,0.40]\rangle$ \\
\hline$A_{2}$ & $\langle[0.43,0.53],[0.29,0.40]\rangle$ \\
\hline$A_{3}$ & $\langle[0.53,0.64],[0.19,0.29]\rangle$ \\
\hline
\end{tabular}

Table 12. The Score Function and the ranking order of the alternatives

\begin{tabular}{|c|c|c|}
\hline Alternatives & $S_{i}$ & Rank \\
\hline$A_{1}$ & 0.18 & 2 \\
\hline$A_{2}$ & 0.14 & 3 \\
\hline$A_{3}$ & 0.34 & 1 \\
\hline
\end{tabular}

\section{Conclusions}

The problem of dealing with transportation, storage and manipulation costs of input raw materials as well as the income earned based on products is highly related to the selection of the location of a production plant.

Table 7. The responses obtained from the first one of the three experts, in the numerical form

\begin{tabular}{|c|c|c|c|}
\hline Alternatives Criteria & $\mathrm{S}$ & $\mathrm{M}$ & $\mathrm{L}$ \\
\hline$A_{1}$ & $\langle[0.35,0.45],[0.45,0.55]\rangle$ & $\langle[0.45,0.55],[0.35,0.45]\rangle$ & $\langle[0.65,0.75],[0.15,0.25]\rangle$ \\
\hline$A_{2}$ & $\langle[0.45,0.55],[0.35,0.45]\rangle$ & $\langle[0.45,0.55],[0.15,0.25]\rangle$ & $\langle[0.35,0.45],[0.45,0.55]\rangle$ \\
\hline$A_{3}$ & $\langle[0.35,0.45],[0.35,0.45]\rangle$ & $\langle[0.45,0.55],[0.35,0.45]\rangle$ & $\langle[0.45,0.55],[0.15,0.25]\rangle$ \\
\hline
\end{tabular}

Table 8 . The responses obtained from the second one of the three experts, in the numerical form

\begin{tabular}{|c|c|c|c|}
\hline Alternatives Criteria & $\mathrm{S}$ & M & $\mathrm{L}$ \\
\hline$A_{1}$ & $\langle[0.45,0.55],[0.35,0.45]\rangle$ & $\langle[0.45,0.55],[0.35,0.45]\rangle$ & $\langle[0.55,0.65],[0.25,0.35]\rangle$ \\
\hline$A_{2}$ & $\langle[0.55,0.65],[0.25,0.35]\rangle$ & $\langle[0.35,0.45],[0.35,0.45]\rangle$ & $\langle[0.35,0.45],[0.45,0.55]\rangle$ \\
\hline$A_{3}$ & $\langle[0.65,0.75],[0.15,0.25]\rangle$ & $\langle[0.65,0.75],[0.15,0.25]\rangle$ & $\langle[0.45,0.55],[0.25,0.35]\rangle$ \\
\hline
\end{tabular}

Table 9. The responses obtained from the third one of the three experts, in the numerical form

\begin{tabular}{|c|c|c|c|}
\hline Alternatives Criteria & S & M & $\mathrm{L}$ \\
\hline$A_{1}$ & $\langle[0.43,0.56],[0.43,0.56]\rangle$ & $\langle[0.43,0.56],[0.31,0.43]\rangle$ & $\langle[0.43,0.56],[0.18,0.31]\rangle$ \\
\hline$A_{2}$ & $\langle[0.68,0.81],[0.06,0.18]\rangle$ & $\langle[0.31,0.43],[0.18,0.31]\rangle$ & $\langle[0.31,0.43],[0.56,0.68]\rangle$ \\
\hline$A_{3}$ & $\langle[0.43,0.56],[0.06,0.18]\rangle$ & $\langle[0.68,0.81],[0.18,0.31]\rangle$ & $\langle[0.68,0.81],[0.06,0.18]\rangle$ \\
\hline
\end{tabular}

Table 10. The group performance ratings

\begin{tabular}{|c|c|c|c|}
\hline Weights & 0.32 & 0.33 & 0.35 \\
\hline Alternatives & $\mathrm{S}$ & $\mathrm{M}$ & $\mathrm{L}$ \\
\hline$A_{1}$ & $\langle[0.41,0.51],[0.38,0.48]\rangle$ & $\langle[0.45,0.55],[0.35,0.45]\rangle$ & $\langle[0.56,0.66],[0.20,0.31]\rangle$ \\
\hline$A_{2}$ & $\langle[0.55,0.65],[0.24,0.34]\rangle$ & $\langle[0.38,0.48],[0.23,0.33]\rangle$ & $\langle[0.35,0.45],[0.45,0.55]\rangle$ \\
\hline$A_{3}$ & $\langle[0.49,0.60],[0.20,0.30]\rangle$ & $\langle[0.58,0.69],[0.20,0.30]\rangle$ & $\langle[0.51,0.62],[0.17,0.28]\rangle$ \\
\hline
\end{tabular}


The effect of the afore mentioned costs can be significantly manifested in the case of raw materials, or intermediate products, which do not suffer significant transportation costs, i.e. the products whose ratios price/ton or price $/ \mathrm{m}^{3}$ is very small. The problem of a site selection becomes much more complex in the case of the materials whose prices can significantly vary in the market, especially when there is a need for long-term predictions.

Therefore, this paper proposes an approach based on linguistic variables and IVIFNs that should provide an adequate selection of a site as well as the consideration of different scenarios.

The proposed approach has a great similarity to the previously proposed approaches based on the use of MCDM methods, especially approaches adapted for decision-making in fuzzy environments. However, the main advantage of this approach is based on the use of IVIFNs, i.e. IFS, that should allow evaluation based on smaller number of, usually more complex, evaluation criteria and incomplete and inaccurate information.

The usability and effectiveness of the proposed approach, i.e. the proposed computational procedure, are demonstrated on an example of site selection for the new smelter and refinery plant. The obtained results prove the usability and efficiency of the proposed approach, which is why the further testing and improvement of the proposed approach have been planned.

\section{References}

Atanassov, K. T. 1994. New operations defined over the intuitionistic fuzzy sets, Fuzzy Sets and Systems 61(2): 137-142. https://doi.org/10.1016/0165-0114(94)90229-1

Atanassov, K.; Gargov, G. 1989. Interval valued intuitionistic fuzzy sets, Fuzzy Sets and Systems 31(3): 343-349. https://doi.org/10.1016/0165-0114(89)90205-4

Atanassov, K. T. 1986. Intuitionistic fuzzy sets, Fuzzy Sets and Systems 20(1): 87-96. https://doi.org/10.1016/S0165-0114(86)80034-3

Atanassov, K.; Pasi, G.; Yager, R. 2002. Intuitionistic fuzzy interpretations of multi-person multi-criteria decision making, in 2002 First International IEEE Symposium Intelligent Systems, 2002: Proceedings, 10-12 September 2002, Varna, Bulgaria. https://doi.org/10.1109/IS.2002.1044238

Badri, M. A. 1999. Combining the analytic hierarchy process and goal programming for global facility location-allocation problem, International Journal of Production Economics 62(3): 237-248.

https://doi.org/10.1016/S0925-5273(98)00249-7

Barda, O. H.; Dupuis, J.; Lencioni, P. 1990. Multicriteria location of thermal power plants, European Journal of Operational Research 45(2-3): 332-346. https://doi.org/10.1016/0377-2217(90)90197-J

Bellman, R. E.; Zadeh, L. A. 1970. Decision-making in a fuzzy environment, Management Science 17(4): B141-B146. https://dx.doi.org/10.1287/mnsc.17.4.B141

Chandra, P.; Fisher, M. L. 1994. Coordination of production and distribution planning, European Journal of Operational Research 72(3): 503-517.

https://doi.org/10.1016/0377-2217(94)90419-7
Chen, S.-M.; Tan, J.-M. 1994. Handling multicriteria fuzzy decision-making problems based on vague set theory, Fuzzy sets and systems 67(2): 163-172.

https://doi.org/10.1016/0165-0114(94)90084-1

Chou, C.-C. 2007. A fuzzy MCDM method for solving marine transshipment container port selection problems, Applied Mathematics and Computation 186(1): 435-444. https://doi.org/10.1016/j.amc.2006.07.125

Chou, S.-Y.; Chang, Y.-H.; Shen, C.-Y. 2008. A fuzzy simple additive weighting system under group decision-making for facility location selection with objective/subjective attributes, European Journal of Operational Research 189(1): 132-145. https://doi.org/10.1016/j.ejor.2007.05.006

De, S. K.; Biswas, R.; Roy, A. R. 2000. Some operations on intuitionistic fuzzy sets, Fuzzy Sets and Systems 114(3): 477-484. https://doi.org/10.1016/S0165-0114(98)00191-2

Dymova, L.; Sevastjanov, P. 2011. Operations on intuitionistic fuzzy values in multiple criteria decision making, Scientific Research of the Institute of Mathematics and Computer Science 10(1): 41-48.

Hong, D. H.; Choi, C.-H. 2000. Multicriteria fuzzy decisionmaking problems based on vague set theory, Fuzzy Sets and Systems 114(1): 103-113. https://doi.org/10.1016/S0165-0114(98)00271-1

Hwang, C.-L.; Lin, M. J. 1987. Group Decision Making under Multiple Criteria: Methods and Applications. Springer. 400 p.

Hwang, C.-L.; Yoon, K. 1981. Multiple Attribute Decision Making: Methods and Applications: a State-of-the-Art Survey. 1 st edition, Springer. 269 p.

Jayaraman, V.; Pirkul, H. 2001. Planning and coordination of production and distribution facilities for multiple commodities, European Journal of Operational Research 133(2): 394-408. https://doi.org/10.1016/S0377-2217(00)00033-3

Keršulienè, V.; Zavadskas, E. K.; Turskis, Z. 2010. Selection of rational dispute resolution method by applying new stepwise weight assessment ratio analysis (SWARA), Journal of Business Economics and Management 11(2): 243-258. https://dx.doi.org/10.3846/jbem.2010.12

Li, D.-F. 2005. Multiattribute decision making models and methods using intuitionistic fuzzy sets, Journal of Computer and System Sciences 70(1): 73-85. https://doi.org/10.1016/j.jcss.2004.06.002

Liang, G.-S.; Wang, M.-J. J. 1991. A fuzzy multi-criteria decision-making method for facility site selection, International Journal of Production Research 29(11): 2313-2330. https://doi.org/10.1080/00207549108948085

Liu, S.; Papageorgiou, L. G. 2013. Multiobjective optimisation of production, distribution and capacity planning of global supply chains in the process industry, Omega: The International Journal of Management Science 41(2): 369-382. https://doi.org/10.1016/j.omega.2012.03.007

Mairs, T. G.; Wakefield, G. W.; Johnson, E. L.; Spielberg, K. 1978. On a production allocation and distribution problem, Management Science 24(15): 1622-1630. https://doi.org/10.1287/mnsc.24.15.1622

Maric, M.; Stanimirovic, Z.; Djenic, A.; Stanojevic, P. 2014. Memetic algorithm for solving the multilevel uncapacitated facility location problem, Informatica 25(3): 439-466. https://doi.org/10.15388/Informatica.2014.23

Mousavi, S. M.; Tavakkoli-Moghaddam, R.; Heydar, M.; Ebrahimnejad, S. 2013. Multi-criteria decision making for plant location selection: an integrated Delphi-AHP-PROMETHEE methodology, Arabian Journal for Science and Engineering 38(5): 1255-1268.

https://doi.org/10.1007/s13369-012-0361-8 
Ray, A.; De, A.; Dan, P. K. 2015. Facility location selection using complete and partial ranking MCDM methods, International Journal of Industrial and Systems Engineering 19(2): 262-276. https://doi.org/10.1504/IJISE.2015.067251

Saaty, T. L. 1977. A scaling method for priorities in hierarchical structures, Journal of Mathematical Psychology 15(3): 234-281. https://doi.org/10.1016/0022-2496(77)90033-5

Shen, F.; Xu, J.; Xu, Z. 2015. An automatic ranking approach for multi-criteria group decision making under intuitionistic fuzzy environment, Fuzzy Optimization and Decision Making 14(3): 311-334. https://doi.org/10.1007/s10700-014-9201-5

Szmidt, E.; Kacprzyk, J. 2002. Using intuitionistic fuzzy sets in group decision making, Control and Cybernetics 31(4): 1037-1053.

Szmidt, E.; Kacprzyk, J. 2000. Distances between intuitionistic fuzzy sets, Fuzzy Sets and Systems 114(3): 505-518. https://doi.org/10.1016/S0165-0114(98)00244-9

Szmidt, E.; Kacprzyk, J. 1996. Remarks on some applications of intuitionistic fuzzy sets in decision making, Notes on Intuitionistic Fuzzy Sets 2(3): 22-31.

Wang, X. 2008. Fuzzy number intuitionistic fuzzy arithmetic aggregation operators, International Journal of Fuzzy Systems 10(2): 104-111.

Wei, G.-W. 2011. Gray relational analysis method for intuitionistic fuzzy multiple attribute decision making, Expert Systems with Applications 38(9): 11671-11677.

https://doi.org/10.1016/j.eswa.2011.03.048

Wei, G.; Zhao, X. 2012. Some induced correlated aggregating operators with intuitionistic fuzzy information and their application to multiple attribute group decision making, Expert Systems with Applications 39(2): 2026-2034. https://doi.org/10.1016/j.eswa.2011.08.031

Wei, G.; Zhao, X.; Lin, R. 2010. Some induced aggregating operators with fuzzy number intuitionistic fuzzy information and their applications to group decision making, International Journal of Computational Intelligence Systems 3(1): 84-95. https://dx.doi.org/10.1080/18756891.2010.9727679

$\mathrm{Xu}, \mathrm{Z}$. 2011. Approaches to multiple attribute group decision making based on intuitionistic fuzzy power aggregation operators, Knowledge-Based Systems 24(6): 749-760. https://doi.org/10.1016/j.knosys.2011.01.011

$\mathrm{Xu}, \mathrm{Z}$.-S. 2007. Methods for aggregating interval-valued intuitionistic fuzzy information and their application to decision making, Control and Decision 22(2): 215-219. (in Chinese).

Xu, Z.-S.; Chen, J. 2007. Approach to group decision making based on interval-valued intuitionistic judgment matrices, Systems Engineering - Theory \& Practice 27(4): 126-133. https://doi.org/10.1016/S1874-8651(08)60026-5

$\mathrm{Xu}, \mathrm{Z}$; Liao, H. 2015. A survey of approaches to decision making with intuitionistic fuzzy preference relations, Knowledge-Based Systems 80: 131-142.

https://doi.org/10.1016/j.knosys.2014.12.034

$\mathrm{Xu}, \mathrm{Z}$; Y Yager, R. R. 2006. Some geometric aggregation operators based on intuitionistic fuzzy sets, International Journal of General Systems 35(4): 417-433. https://doi.org/10.1080/03081070600574353

Zadeh, L. A. 1965. Fuzzy sets, Information and Control 8(3): 338-353. https://doi.org/10.1016/S0019-9958(65)90241-X 